\title{
The Effect of short circuit fault in three-phase core-typed transformer
}

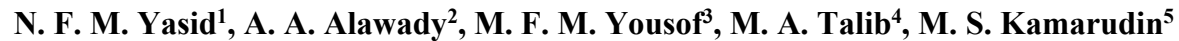 \\ 1,2,3,5 Faculty of Electrical and Electronic Engineering, Universiti Tun Hussein Onn Malaysia, Malaysia \\ ${ }^{2}$ Department of Computer Technical Engineering, College of Technical Engineering, Islamic University, Iraq \\ ${ }^{4}$ Tenaga Nasional Berhad Research, Kawasan Institusi Penyelidikan, 43000 Kajang, Selangor, Malaysia
}

\begin{tabular}{ll}
\hline \hline Article Info & ABSTRACT \\
\cline { 2 - 2 } Article history: & $\begin{array}{l}\text { Different techniques for monitoring the transformer condition are } \\
\text { continuously discussed. This is due to the fact that transformers are one of } \\
\text { the most expensive components in the power system network. Not to } \\
\text { Revised Oct 25, 2019 }\end{array}$ \\
mention the cost to fix any failure occurred in the transformer that have \\
becoming more expensive nowadays. Frequency response analysis (FRA) is \\
found to be the best method to monitor the transformer reliability. This paper \\
presents a continuation of study presented in previous paper [1]. The study \\
performed a laboratory test to show that the response of a normal winding \\
phase A can be affected by short circuit fault which occurred at LV winding \\
phase a, b, and c. To further investigate, current paper performed FRA \\
measurement and applied fault on all phases. The same procedure is repeated \\
on a distribution transformer to verify the findings. This is to examine the \\
effect of fault at winding of other phases to the response of measured phase.
\end{tabular}

This is an open access article under the CC BY-SA license.

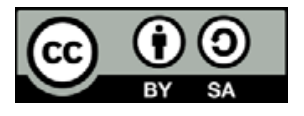

\section{Corresponding Author:}

Nurul Farahwahida bt Md Yasid,

Department of Electrical and Electronic Engineering,

Universiti Tun Hussein Onn Malaysia (UTHM),

86400, Parit Raja, Batu Pahat, Johor, Malaysia.

Email: farahwahida.yasid@gmail.com

\section{INTRODUCTION}

Transformers are exposed to various electrical and mechanical failures during their lifespan. Some of these were caused by mishandling during maintenance and transportation, earthquake, and even external faults. Extended outages, costly repairs and potentially serious fault mostly occurred to transformer active parts which are the core and windings. It is found that, core damage is more likely as a result of shocks cause by transportation, while winding damage is caused by short circuit (SC) forces [2,3]. To assess the condition and mechanical reliability of transformers, frequency response analysis (FRA) is proven to be a powerful and effective method [4-8]. It is highly sensitive to electrical or mechanical changes in transformers. For example, [9] has presented the effect of shunt impedance, high voltage bushing and length of measurement lead in the response. In [10], the reference observed the response sensitivity towards the capacitance and mutual inductance between the windings. Reference [11] studied the response sensitivity towards temperature and moisture content of the transformer insulation. It showed there is a considerable change in the response indicating that it is highly sensitive even on non-mechanical factor. Reference [12] had reviewed literature related to the aspect that must be considered when implementing SFRA method, which is connection of non-tested terminals when diagnosing winding failures. Reference [13] has found that the winding response of an autotransformer can be affected by the tertiary winding due to coupling effect between windings. More studies are necessary to further understand this sensitivity of FRA measurement. 
This paper is proposing to investigate the effect of fault which occurred in other winding on the response of the measured winding. The measurements in this study were conducted on three-phase transformers at a local research utility company. FRA end-to-end open circuit test is used, and the fault is short circuit turns that was created by shorting the terminals on the tap changers.

\section{SHORT CIRCUIT FAULT IN TRANSFORMER WINDING}

According to [14], faulty winding usually occurs in distribution transformers. This is because the current flow in the primary winding undergoes electromagnetic induction voltage which is stepped down. The current is then stepped up in the secondary winding. During this process, the secondary windings have to withstand electrical, thermal and mechanical stresses [15]. Several types of faulty windings such as the SC fault commonly occurred due to these stresses. The occurence of SC is quite rare, but the probability is increased during the transformer lifetime which is typically up to 50 years [16]. In spite of this, according to [3], about $40 \%$ of the transformer faults are initiated by huge impact of SC every year.

One of the sources contribute to SC fault is insulation breakdown. Insulation breakdown usually occurs due to high current and voltage which is above the rated values. The breakdown of the insulation results in flashover between two turns and causes inter-turn SC fault. Besides that, thermal losses in copper will produce hotspots in the winding. This over time causes tear of the insulation and decrease of the physical strength up to the point of breaking of the winding. Ultimately, causing SC fault in the winding. According to [17], SC faults are divided into three basic categories. These are winding-to-ground fault, winding-towinding fault, and turn-to-turn fault on the same winding. Turn-to-turn or inter-turn short SC fault is the most commonly to occur. Figure 1 illustrates the occurrence of inter-turn SC fault due to insulation breakdown.

In general, SC in the winding causes reduction of the winding electrical length. In case of winding coupled with magnetic core, the main sign of internal short-circuit fault is a significant increase of first antiresonance in frequency response corresponding to open secondary winding [18]. The frequency range is typically several $\mathrm{Hz}$ up to few $\mathrm{kHz}$, which is the low frequency (LF) region. The key point to understand the LF variation affected by shorted turns can be obtained in the description of Faraday's law in the shorted turns. The law states that the "electromagnetic force (emf) induced in a turn is equal to the rate of variation of the electromagnetic flux inside it" [19]. The paper also presents finite-element method (FEM) showing the changes of magnetizing characteristics of core, which causes the LF deviation. This important property can be used as one of the main indications of winding SC fault. However, it must be remembered that the deviation of the LF responses is not a sign the presence of the SC in the winding under measurement only, because the increases occur in the frequency responses of all windings on the same core [20].

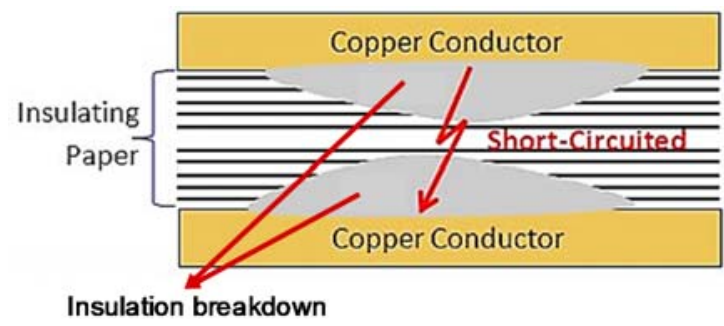

Figure 1. Inter-turn short circuit due to insulation breakdown

\section{MEASUREMENT PROCEDURE}

3.1. Details of experimental transformer

The basic details of the transformers used in this paper are given in Table 1 and Table 2.

Table 1: Details of 360VA experimental transformer

\begin{tabular}{cc}
\hline Attributes & Details \\
\hline Model & KTS 10MT-3/360 VA \\
Capacity & Three-phase, \\
High voltage winding & experimental transformer of 360VA \\
Low voltage winding & 240 V Delta connected \\
Current & $3 \times 60$ V Star connected \\
& $2 \mathrm{~A}$ \\
\hline
\end{tabular}

Table 2: Details of 500kVA distribution transformer

\begin{tabular}{cc}
\hline Attributes & Details \\
\hline Model & ONAN TRANSFORMER \\
& DRG. No. MTM 11/3/1-D \\
Manufactured date & $21 / 06 / 1984$ \\
Capacity & Three-phase, $50 \mathrm{~Hz}, 500 \mathrm{kVA}$ \\
Vector group & Dyn 11 \\
Oil & $672 \mathrm{~L}-578 \mathrm{Kg}$ \\
\hline
\end{tabular}




\subsection{FRA measurement connection}

FRA configuration used is the end-to-end open circuit test. Measurement is conducted per phase with the secondary winding is left open circuit. The study is conducted by measuring and comparing the FRA response before and after the presence of SC fault in the winding. In this study, the FRA measurement is conducted on the $\mathrm{HV}$ winding of phase $\mathrm{A}, \mathrm{B}$ and $\mathrm{C}$ one after another. While the fault is applied at the LV winding of phase $\mathrm{a}, \mathrm{b}$ and $\mathrm{c}$ consecutively. This is to observe whether fault at winding of other phases can actually affect the response of measured phase.

Figure 2(a) shows a short and thin cable was used to connect between two terminals (shown in circle) of a Dyn11, 360VA transformer. This causes $1 / 3$ of the total LV winding to be shorted or removed from the main winding. Figure 2(b) shows the schematic diagram of the short circuit fault. On the other hand, the fault in second transformer is created by connecting a cable to the exposed transformer taps in each phase. This is shown in Figure 3. Figure 3(a) shows the physically simulated short circuit fault on tap 3-4 of phase B and Figure 3(b) shows the schematic diagram of the simulated fault.

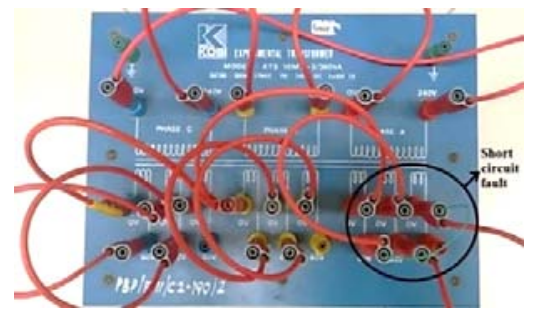

(a)

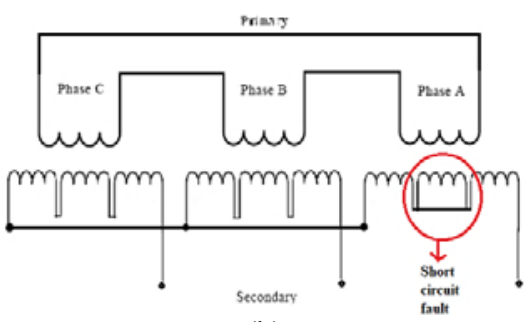

(b)

Figure 2. (a) SC fault on LV winding of phase A, (b) Schematic diagram of the winding and fault location.

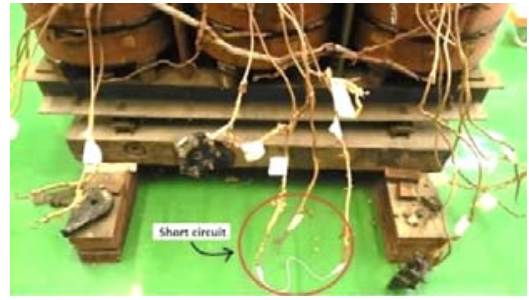

(a)

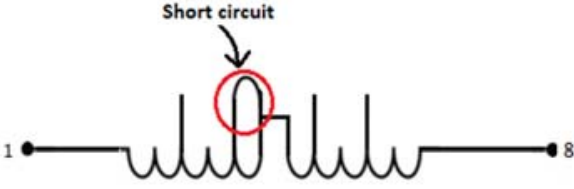

(b)

Figure 3. (a) SC fault on tap 3-4 of phase B, (b) Schematic diagram of the winding and fault location

\section{THE ANALYSIS OF SHORT CIRCUIT EFFECT TO OTHER WINDING PHASES}

Figure 4 and Figure 5 show the frequency responses of two different transformers before the fault is simulated on the transformer windings.

From Figure 4, the low frequency region of FRA response for phase B, which is middle phase winding shows a slight variation from the other two phases. As discussed in [13], this is due to the magnetic path of middle phase which is slightly different from the side phases (side limbs). Meanwhile, the variation of FRA responses at medium frequency region is affected by the three-phase coupling between the windings.

Figure 5 shows the measured responses of end to end open circuit test on the 500kVA transformer. Clearly it shows there are slight variations between phases A, B and C. Such variation is due to the condition of the transformer which is not new. The transformer itself was manufactured in 1984 and was taken out of service due to a fault near bushing. The windings have several dents, but these were minimal. The turn ratio and winding resistance test for both transformers indicate that the windings are still in good conditions.

\subsection{Response phase $A$}

Figure 6 shows the responses where FRA measurement is conducted at phase A of HV winding. The short circuit fault is simulated on phase a, b and c of LV winding consecutively. From Figure 6, response 'Normal A' represents the response before the short circuit fault is applied on the winding. The other responses represent the response after fault have applied on the winding respectively. 


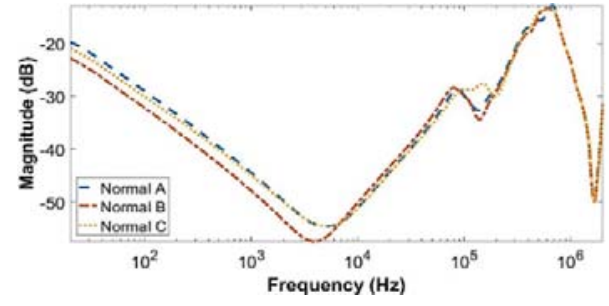

Figure 4. FRA response on normal winding condition of 360VA transformer

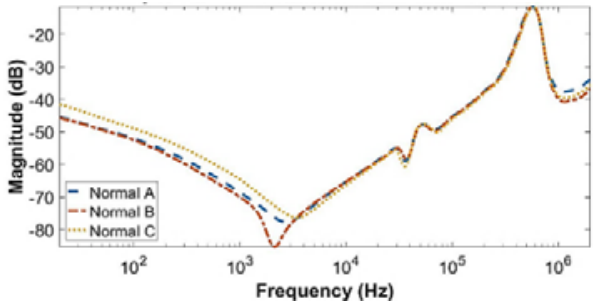

Figure 5. FRA response on normal winding condition of 500kVA transformer

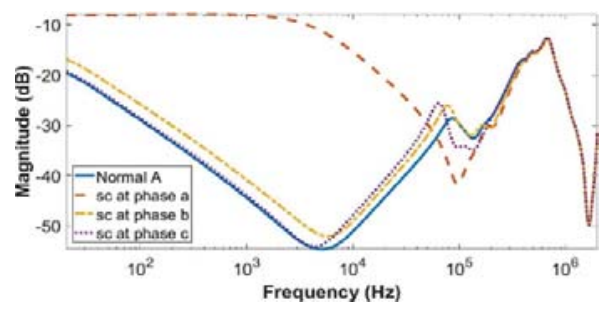

Figure 6. Frequency responses of phase A from 360VA transformer

Figure 6 shows the comparison of response normal A and when SC fault has occurred on its LV winding. It is the result of the FRA measurement that was conducted at the same phase as the faulty winding. The response significantly shifted to right, towards higher frequencies. This can be explained using (1),

$$
\Phi \propto N I
$$

Equation (1) shows that the amount of flux, $\Phi$ is directly proportional to the product of the number of turns, $N$ and the current flow in the winding, $I$. In general, the internal SC leads to reduction of the electrical length of the winding, meaning reduction of $N$ [20]. When the number of turns reduces, the flux formed in the coil also reduced. As a result, during SC fault, the magnetizing inductance of the right-side limb is drastically reduced and caused the magnitude in low frequency region to increase. The large amount of shift is affected by the magnetizing inductance in the limb of the core caused by the SC fault in the secondary winding of the same phase. It causes a substantial effect in the response of phase A.

Figure 6 also shows the responses when SC fault is on phase b (LV winding). The response of LF region is seen to be slightly shifted towards higher frequencies. The shifting is much less when compared to the previous case. This is because the faulty is not located at the same phase as the measured winding. Finally, for response when fault occurred in phase c, the initial antiresonance of the response is marginally shifted towards higher-frequencies. The degree of shifting is smaller when compared to the previous cases. This is because the fault occurred at winding phase $\mathrm{c}$ that is located furthest away from the measured winding (Phase A). Basically, the response of winding phase A when faulty in phase b shifted more compared to when fault in phase c. This can be explained with the help of Figure 7, (2) and (3).

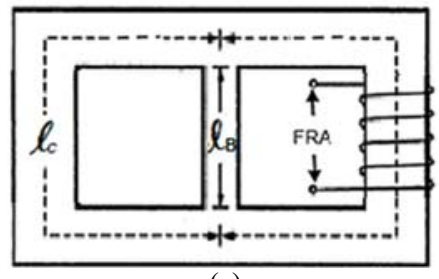

(a)

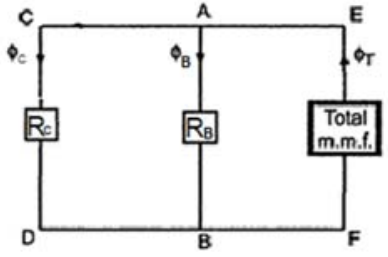

(b)

Figure 7. (a) The core of a three-phase transformer with FRA measurement at phase A, (b) Equivalent magnetic circuit of FRA measurement at phase A 
Where $R_{B}$ is the reluctance of central limb (phase $\mathrm{B}$ ), $R_{C}$ represents the reluctance of left-side limb (phase $C$ ), $l_{B}$ is the length of central limb (phase B), ${ }_{C}$ is the length of left-side limb (phase $C$ ), $\mu$ is the magnetic permeability which is the product of $\mu_{o} \mu_{r}$ and $A$ is the cross-sectional area refers to geometry of the core.

$$
R_{X}=\frac{l_{X}}{\mu A}
$$

From Figure 7, when FRA measurement is performed at winding of phase A, current flows in the winding and flux is produced in the core. The flux flow in the core and pass through each limb. The length of flux path flowing from phase $\mathrm{A}$ (source) and pass through the central limb, $l_{\mathrm{B}}$ (phase $\mathrm{B}$ ) is measured from point $\mathrm{E}, \mathrm{A}, \mathrm{B}$ to $\mathrm{F}$. Meanwhile, the length of flux path for the left-side limb, $l_{\mathrm{C}}$ (phase $\mathrm{C}$ ) is measured from point $\mathrm{E}, \mathrm{A}, \mathrm{C}, \mathrm{D}, \mathrm{B}$ to $\mathrm{F}$. The $l_{\mathrm{B}}$ is shorter compared to the $l_{\mathrm{C}}$, thus the reluctance of the central limb $\mathrm{R}_{\mathrm{B}}$ is lower than $R_{C}$ as in (2). $x$ in (2) is either phase $A, B$ or $C$. As the reluctance of the central limb, $R_{B}$ is lower, the flux that pass through central limb, $\Phi_{B}$ is higher than the flux in left-side limb, $\Phi_{C}$.

$$
\text { back emf }=4.44 N f \Phi m
$$

Now that we have established that $\Phi_{B}$ is higher than $\Phi_{C}$, let relate the flux with the back EMF. Theoretically, the back EMF of phase B is higher compared to back EMF of phase C. This is because $\Phi_{\mathrm{B}}$ is higher than $\Phi_{\mathrm{C}}$ as referred to (3). As a result, the response when the fault is at phase b is more affected compared to fault at phase $\mathrm{c}$ as can be seen in Figure 6.

Figure 8 shows the FRA response for Dyn11, 500kVA transformer where the measurement is conducted at Phase A, while the SC fault is simulated on phase a, b and c winding consecutively. Clearly, when fault is simulated at the same phase, the response significantly shifted towards higher frequency. It is also shown that response due to faulty in phase $\mathrm{b}$ shifted more compared to faulty in phase $\mathrm{c}$. This finding is similar to the previous case on the first transformer.

\subsection{Response phase $B$}

In this case, the FRA measurement is conducted at winding of the middle limb, phase B, while fault is applied on the LV windings consecutively. The measured responses are given in Figure 9.

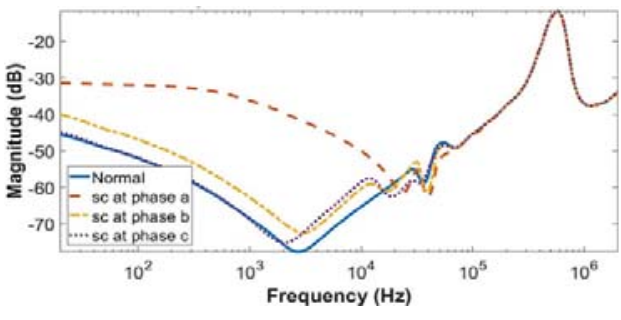

Figure 8. Frequency response of phase A from 500 kVA transformer.

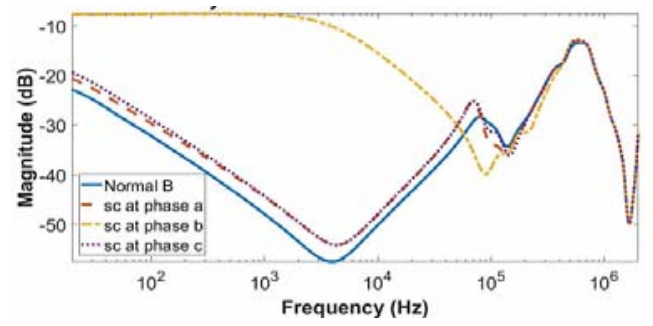

Figure 9. Frequency response of phase B for 360VA transformer

From Figure 9, the response shows different pattern of effect when compared to the previous case. In this case, the response when SC fault occurred in the phase a and c affected almost similarly. This is because the fault is on phase a and $c$ that are located adjacent to the measured phase which is phase $b$. This can be explained by Figure 10 and (2).

From Figure 10, when FRA measurement is performed at HV winding of phase B, current flows in the winding and flux is produced in the core. The length of the flux path flowing from phase $\mathrm{B}$ (source) and pass through the right-side limb, $1_{A}$ (phase A) is considered from point E, C, D to F. Meanwhile, the length of flux path for the left-side limb, $1_{C}$ (phase $\mathrm{C}$ ) is measured from point $\mathrm{E}, \mathrm{A}, \mathrm{B}$ to $\mathrm{F}$. The length for both flux path is similar, thus the reluctance for both right and left-side limb, $\mathrm{R}_{\mathrm{A}}$ and $\mathrm{R}_{\mathrm{C}}$ are also similar. This can be prove using equation (2). As the reluctance of both limbs are similar, the flux that pass through in both right and left side limb are also similar. In addition to that, $\Phi_{\mathrm{A}}$ is almost similar to $\Phi_{\mathrm{C}}$. Therefore, the back EMF of phase A is also almost similar to back EMF of phase $\mathrm{C}$ as referred to (3). For this reason, the FRA response when short circuit fault occurs in phase a and c, the response is almost similarly affected as can be seen in Figure 9. 
On the other hand, when the fault is located at the same phase of the measured winding, the effect of fault on the response is very large. This is similar to the case of FRA measurement on phase A and fault is on phase a.

Again, the procedure is repeated on the second transformer to verify this initial finding. Figure 11 shows the FRA responses for Dyn11, 500kVA transformer when measurement is conducted at phase B.

From figure 11, the FRA response for SC fault at phase a and c shows a slight variation. Here, we are expecting that responses of phase B with fault at phase a and phase c will have similar variations. However, both responses are not exactly similar. This is probably due to the condition of the winding (phase a and c) itself which are not perfectly identical even though the same faults are being applied. As mentioned earlier, this is a transformer that manufactured more than 30 years ago. Therefore, such slight different between fault at phase a and fault at phase $\mathrm{c}$ is acceptable.

\subsection{Response phase $C$}

The last case presents the FRA measurement conducted at the HV winding of the left-side limb or phase $\mathrm{C}$, while the faulty winding is on the $\mathrm{LV}$ winding of phase $\mathrm{a}, \mathrm{b}$ and c consecutively as previous cases.

Figure 12(a) shows the responses experience the same pattern as in the first case where the measurement is conducted on phase A. Basically if the fault located on the same phase as measured winding, the effect on response is huge. On the other hand, if the fault is located further away from the measured winding, the effect is smaller or reduced. Similar trend can be seen on the second transformer as shown in Figure 12(b). These results verify the initial finding in [1]. Table 3 shows the summary of the results obtained.

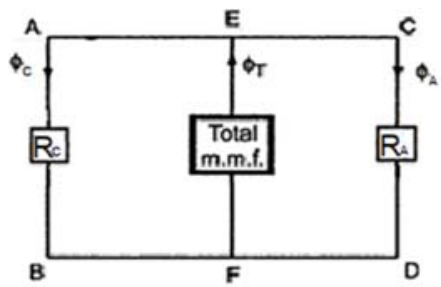

Figure 10. Equivalent magnetic circuit of FRA measurement conducted at phase B

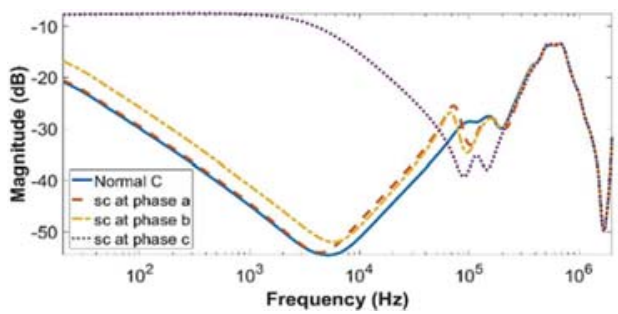

(a)

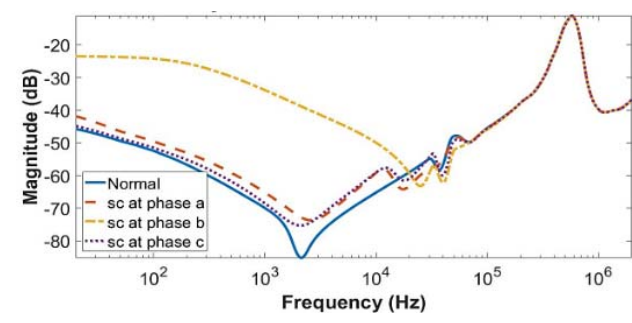

Figure 11. Frequency response of phase B for $500 \mathrm{kVA}$ transformer

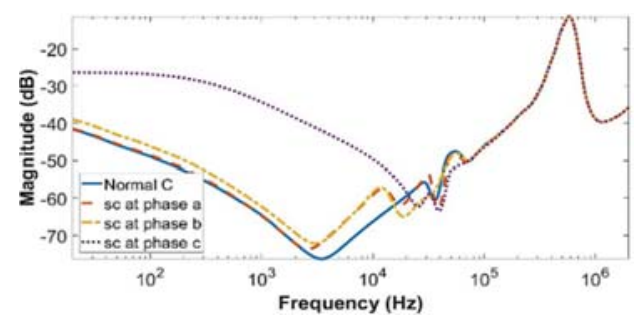

(b)

Figure 12. Frequency response of phase C for (a) 360VA transformer, (b) 500kVA transformer

Table 3: The effect of fault on one winding to response of other windings

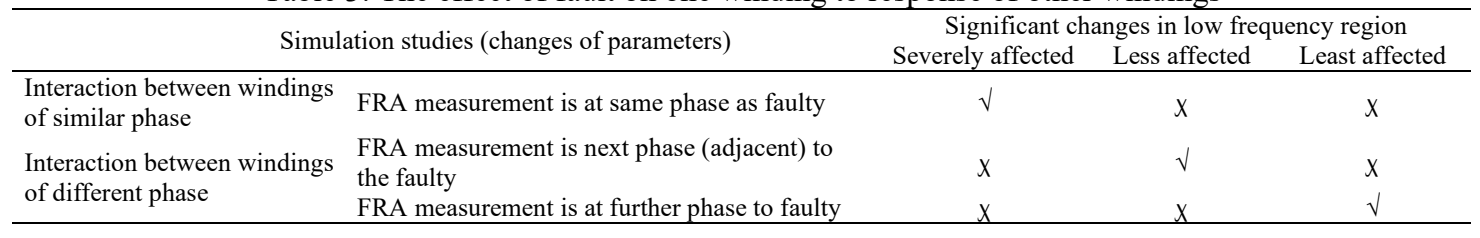

\section{CONCLUSION}

As a conclusion, it was proven that faulty occurred in winding of other phases could actually affect the response of measured phase winding. The location of the faulty winding determines how severe it is 
affecting the measured response. From this finding, it can be concluded that when faulty is at the same phase as the measured winding, it will cause major variation on the response. The response will significantly be shifted towards higher frequencies. Meanwhile, when the faulty is near or adjacent to the measured phase winding, the response will moderately be affected. In case of FRA measurement is conducted in the middle limb, responses of both right and left side limbs will be affected almost similarly. Finally, as the faulty winding is located furthest away from the measured phase winding, the response will be slightly shifted towards higher frequencies.

\section{ACKNOWLEDGEMENTS}

The authors would like to thank the TNB Research for the provision of test facilities and great support for the experimental tests. This work is supported financially by the Islamic University research grant PRG-IUNAJAF-2019.

\section{REFERENCES}

[1] N. F. M. Yasid, M. F. M. Yousof, R. A. Rahman, H. Zainuddin, and S. A. Ghani, "The effect of short circuit fault on one winding to other windings in FRA," International Journal of Power Electronics and Drive Systems (IJPEDS), vol. 10, no. 2, 2019.

[2] G. M. Kennedy, A. J. Mcgrail, J. A. Lapworth, and D. Engineering, "Transformer sweep frequency response analysis ( SFRA )," Energize, pp. 28-33, 2007.

[3] D. Zhou, Z. Li, C. Ke, and Z. Hao, "Simulation of transformer windings mechanical characteristics during the external short-circuit fault," IEEE conference on Electric Utility Deregulation and Restructuring and Power Technologies, pp. 1068-1073, 2015.

[4] A. Kraetge, M. Krüger, J. L. Velásquez, M. Heindl, and S. Tenbohlen, "Experiences with the practical application of Sweep Frequency Response Analysis ( SFRA ) on power transformers," in 16th International Symposium on High Voltage Engineering, pp. 1-6, 2009.

[5] M. Bagheri, M. Naderi, T. Blackburn, and T. Phung, "Frequency response analysis and short-circuit impedance measurement in detection of winding deformation within power transformers," IEEE Electrical Insulation Magazine, vol. 29(3), pp. 33-40, 2013.

[6] A. Kraetge and M. Krüger, "Frequency response analysis - status of the worldwide standardization activities," IEEE, vol. 978, pp. 1-4, 2008.

[7] A. Pandya and B. R. Parekh, "Interpretation of sweep frequency response analysis (SFRA) traces for the open circuit and short circuit winding fault damages of the power transformer," International Journal of Electrical Power and Energy Systems, vol. 62, pp. 890-896, 2014.

[8] M. F. M. Yousof, C. Ekanayake, and T. K. Saha, "Locating inter-disc faults in transformer winding using frequency response analysis," Power Engineering Conference (AUPEC), 2013 Australasian Universities, no. October, pp. 1-6, 2013.

[9] M. Wang, a. J. Vandermaar, and K. D. Srivastava, "Improved detection of power transformer winding movement by extending the FRA high frequency range," Power Delivery, IEEE Transactions on, vol. 20(3), pp. 1930-1938, 2005.

[10] M. F. M. Yousof, "Frequency response analysis for transformer winding condition monitoring," University of Queensland, 2015

[11] M. F. M. Yousof, C. Ekanayake, and T. K. Saha, "Examining the ageing of transformer insulation using FRA and FDS techniques," IEEE Transactions on Dielectrics and Electrical Insulation, vol. 22, no. 2, pp. 1258-1265, 2015.

[12] J. R. Secue and E. Mombello, "Sweep frequency response analysis (SFRA) for the assessment of winding displacements and deformation in power transformers," Electric Power Systems Research, vol. 78, pp. 1119-1128, 2008.

[13] D. M. Sofian, Z. Wang, and J. Li, "Interpretation of transformer FRA responses - Part II: Influence of transformer structure," IEEE Transactions on Power Delivery, vol. 25, no. 4, pp. 2582-2589, 2010.

[14] S. T. Jan, R. Afzal, and A. Z. Khan, "Transformer failures, causes \& impact," International Conference Data Mining, Civil and Mechanical Engineering (ICDMCME'2015), vol. 4, no. 4, pp. 49-52, 2015.

[15] W. H. Bartley, "An International Analysis of Transformer Failures, Part 2," International Association of Engineering Insurers (IMIA), vol. 78, no. 1, 2005.

[16] G. D. Hermann, "Short-circuit withstand capability of power transformers," 2015.

[17] Kasztenny, M. Thompson, and N. Fischer, "Fundamentals of short-circuit protection for transformers," $201063 \mathrm{rd}$ Annual Conference for Protective Relay Engineers, vol. 2, no. 3, pp. 4-7, 2010.

[18] W. H. Portilla, G. A. Mayor, J. P. Guerra, and C. Gonzalez-garcia, "Detection of transformer faults using frequency-response traces in the low-frequency bandwidth," IEEE Transactions on Industrial Electronics, vol. 61(9), pp. 4971-4978, 2014.

[19] V. Behjat, A. Vahedi, A. Setayeshmehr, H. Borsi, and E. Gockenbach, "Diagnosing shorted turns on the windings of power transformers based upon online FRA using capacitive and inductive couplings," IEEE Transactions on Power Delivery, vol. 26, no. 4, pp. 2123-2133, 2011.

[20] V. S. Larin, "Internal short-circuits faults localization in transformer windings using FRA and natural frequencies deviation patterns," CIGRE Study Committee A2 COLLOQUIUM, no. October, pp. 1-14, 2017. 


\section{BIOGRAPHIES OF AUTHORS}

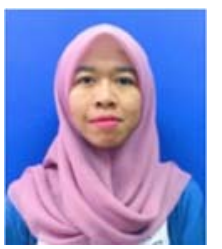

Nurul Farahwahida bt Md Yasid received her bachelor's degree in Electrical Engineering from Universiti Tun Hussein Onn Malaysia (UTHM) in 2017. She is currently pursuing her master's degree in electrical engineering at Universiti Tun Hussein Onn Malaysia. Her research interest includes high voltage equipment and condition monitoring of transformer using FRA.

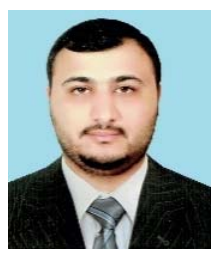

Ahmed Allawy Mohammed Alawady received B.Eng. in Electrical from University of Kufa, Iraq in 2007. He received M.Eng. in Electrical power system from (SHUATS), India in 2012. He is a lecturer at the Department of Computer Technical Engineering, Collage of Technical Engineering at Islamic University, Iraq since 2007. Currently he is pursuing Ph.D. Degree in Universiti Tun Hussein Onn Malaysia. His research is on motors faults detection using FRA.

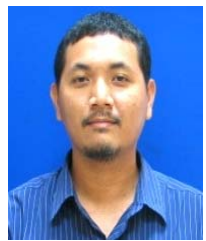

Mohd Fairouz Mohd Yousof received Dip.Eng, B.Eng. and M.Eng. from Universiti Teknologi Malaysia (UTM) in 2005, 2008 and 2010, respectively. In 2015, he obtained Ph.D. degree from The University of Queensland, Australia. He is with the Department of Electrical Power Engineering at Universiti Tun Hussein Onn Malaysia since 2009. He was a visiting researcher at Tenaga Nasional Berhad Research from 2018 to 2019. His main research is condition based monitoring and assessment of transformer and rotating machine.

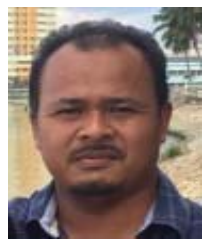

Mohd Aizam Talib has over 19 years of experiences in dealing with transformer diagnostic, condition and life assessment and failure analysis of power transformer. After graduated, he has worked with ABB Transmission and Distribution Sdn Bhd as Design Engineer and in 1998; he has joined TNB Research Sdn Bhd as Research Engineer. He is currently holding a position as Technical Expert (Transformer) with TNB Research Sdn Bhd.

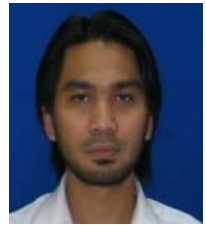

Muhammad Saufi bin Kamarudin obtained his B.Eng. and M.Eng. Degrees in Electrical Engineering (Power) from Universiti Teknologi Malaysia (UTM) in 2003 and 2005, respectively, and a Ph.D. in High Voltage Engineering from Cardiff University, UK, in 2014. Currently, he is a senior lecturer in the Faculty of Electrical \& Electronic Engineering at Universiti Tun Hussein Onn Malaysia (UTHM). His research interests include gas discharges, high voltage surge arresters, and dielectrics and electrical insulation system. 